\title{
Viajes y turismo asociados a la explotación sexual comercial de niños, niñas y adolescentes en Colombia: pornografía infantil*
}

\author{
Carlos Ernesto Sánchez Hernández**
}

Recibido: 12 de octubre de 2018 - Aprobado: 18 de enero de 2019

\section{Resumen}

Las implicaciones del mal denominado turismo sexual asociado a la explotación comercial de niños, niñas y adolescentes en Colombia y sumado a la pornografía infantil han conllevado que los diferentes Estados implementen medidas en contra de este flagelo que permitan materializar la especial y doble protección de los menores de edad como sujetos de derechos, realidad que se ha sido visibilizada por los medios de comunicación, que han abierto un debate frente a las políticas públicas y su eficacia, para lo cual el Estado colombiano ha incrementado penas como respuesta normativa. La presente investigación se enmarca desde la metodología de investigación cualitativa, que evidencia el método de investigación descriptivo. Sus objetivos se circunscribieron a identificar la naturaleza jurídica del marco normativo de la explotación sexual comercial de niños, niñas y adolescentes

\footnotetext{
Este artículo es producto resultado de investigación del PIC-DER-2419 bajo la tutoría del profesor Misael Tirado Acero, en la Línea de Investigación Política Criminal, Derecho Penal y Criminología del Grupo de Investigación Red de Estudios Sociojurídicos Comparados y Políticas Públicas (REsCYPP). Proyecto de investigación: Viajes y turismo asociados a la explotación sexual de NNA en Colombia - pornografía infantil. Facultad de Derecho, Universidad Militar Nueva Granada, Bogotá, Colombia. Citar como: Sánchez Hernández, C. E. (2019). Viajes y turismo asociados a la explotación sexual comercial de niños, niñas y adolescentes en Colombia: pornografía infantil. Revista IUSTA, 51(2), 135-152. DOI: https://doi.org/10.15332/25005286.5036

** Estudiante de Derecho de la Universidad Militar Nueva Granada, Bogotá, Colombia. Orcid: https:// orcid.org/0000-0002-7201-9025-1314, u0303269@unimilitar.edu.co
} 
en Colombia, desde la pornografía infantil, y a determinar la referenciada temática desde el escenario de viajes y turismo.

Palabras clave: control de convencionalidad, norma constitucional integrada, trata de personas.

\title{
Travel AND TOURISM ASSOCIATED WITH THE COMMERCIAL SEXUAL EXPLOITATION OF CHILDREN AND ADOLESCENTS IN COLOMBIA: CHILD PORNOGRAPHY
}

\begin{abstract}
The implications of the so-called sex tourism associated with the commercial exploitation of children and adolescents in Colombia in addition to child pornography have led the different States to implement measures against this scourge that allow for the special and double protection of minors as subjects of rights, reality that has been made visible by the media, who have opened a debate about public policies and their effectiveness, for which the Colombian State has increased penalties as a normative response. This research is framed in the qualitative research methodology, which shows the method of descriptive research. Its purposes were circumscribed to identifying the legal nature of the normative framework of commercial sexual exploitation of children and adolescents in Colombia, from child pornography, and to determine the mentioned topic from the travel and tourism scenario.
\end{abstract}

Keywords: conventionality control, integrated constitutional norm, trafficking in persons.

\section{VIAGENS E TURISMO ASSOCIADOS À EXPLORAÇÃO SEXUAL COMERCIAL DE CRIANÇAS E ADOLESCENTES NA Colômbia: PORNOGRAFIA INFANTIL}

\section{Resumo}

As implicações do equivocadamente denominado turismo sexual associado à exploração comercial das crianças e adolescentes na Colômbia e aditado que a pornografia infantil tem acarretado que os diferentes Estados implementem medidas em contra de este flagelo que permitam materializar a especial e dupla proteção dos menores 
de idade como sujeitos de direitos, realidade que tem sido visibilizada pela mídia, que tem iniciado um debate perante às políticas e sua eficácia, pelo qual o Estado colombiano tem incrementado penas como resposta normativa. Esta pesquisa se foca desde a metodologia da pesquisa qualitativa, que evidencia o método de pesquisa descritiva. Seus objetivos se circunscreveram em identificar a natureza jurídica do marco normativo da exploração sexual comercial de crianças e adolescentes na Colômbia, desde a pornografia infantil e determinar a referenciada temática desde o cenário de viagens e turismo.

Palavras-chave: controle de convencionalidade, norma constitucional integrada, tráfico de pessoas.

\section{Introducción}

El ordenamiento jurídico colombiano en su lucha contra el flagelo de la explotación sexual comercial de niños, niñas y adolescentes (ESCNNA) ha ido ratificando un sinnúmero de protocolos, tratados, acuerdos, convenios, entre otros, y en esa interiorización de normativa internacional que se refiere a los derechos humanos, el derecho internacional de los derechos humanos, el derecho internacional humanitario, en que están involucrados los menores de edad, el Estado colombiano mediante su norma constitucional integrada o bloque de constitucionalidad ha ido dando tratamiento normativo en materia de protección y reivindicación de derechos a un grupo poblacional vulnerable y vulnerado, que, por lo general, ha estado invisibilizado desde el aparataje estatal y expuesto a dinámicas del mercado ilegal que opera en los viajes y el turismo, que busca menores de edad para el mercado del sexo, sumado al consumo de drogas ilegales.

En este sentido, a pesar del blindaje normativo y de la política pública en materia de protección, es necesario preguntarse hasta qué punto es el Estado colombiano permisivo con este tipo de abuso a los derechos de niños, niñas y adolescentes, y cuál es su accionar para frenar una cruda realidad que se visibiliza cada día mas. Si bien en lo referido a Colombia existen leyes que castigan a quienes transgredan los derechos de niños, niñas y adolescentes, acciones que se encuentran tipificadas como delitos en el Código Penal (Ley 599/2000, de 24 de julio), la Ley 1236/2008, de 23 de julio y la Ley 1098/2006, de 8 de noviembre, entre ellos, artículos específicos contra la pornografía con menores de edad (art. 218) y la utilización o facilitación 
de medios de comunicación para ofrecer servicios sexuales de menores (art. 219-A). Estos artículos entrañan una amplia denotación de las penas que se les imponen a quienes contrarían la ley y delinquen con niños, niñas y adolescentes, amparados por el Código de Infancia y Adolescencia (Ley 1098/2006, de 8 de noviembre), el cual posee principios, finalidades y derechos que deben ser cumplidos y respetados por toda la sociedad.

Pese a estos tratamientos jurídicos que conllevan la penalización, en muchas ciudades de Colombia se vulneran los derechos a la integridad sexual de los menores de edad, no solo desde el abuso sexual, la violencia sexual, sino desde las mismas dinámicas comerciales que vuelven objeto a un menor de edad, siendo subterráneo, o pasando desapercibido, o a pesar de ser visible no teniendo el adecuado manejo por los funcionarios o las instituciones que deben ser garantes de la protección de niños, niñas y adolescentes, lo cual implicaría la necesidad de plantearse una responsabilidad del Estado por acción u omisión al no cumplir lo emanado en la misma política pública, la cual no necesariamente termine endilgándose en una corresponsabilidad con la sociedad y la familia, como siempre sucede. Esta investigación parte de una revisión documental, exploratoria y descriptiva que profundiza en algunos conceptos para poder evidenciar una realidad que vulnera en sus principios y derechos a un grupo poblacional.

Para ello, es necesario mencionar el Código de Infancia y Adolescencia en su artículo 1:

Este código tiene por finalidad garantizar a los niños, a las niñas y a los adolescentes su pleno y armonioso desarrollo para que crezcan en el seno de la familia y de la comunidad, en un ambiente de felicidad, amor y comprensión. Prevalecerá el reconocimiento a la igualdad y la dignidad humana, sin discriminación alguna. De tal concepto surgen características propias de este derecho que es una parte del ordenamiento jurídico, su contenido normativo se ocupa de la imposición de penas y medidas de seguridad impuestas a quienes infringen la ley. (Ley 1098/2006, de 8 de noviembre)

Por ello, el análisis práctico de las políticas del sistema jurídico debe conllevar una correcta gestión de este en que no se vulneren los principios de niños, niñas y adolescentes, teniendo en cuenta su no revictimización. Los medios de comunicación llevan a la palestra de lo público esta cruel realidad en la que niños, niñas y 
adolescentes, no solo están expuestos a las redes criminales que a través de la pornografía infantil promueven encuentros eróticos y sexuales tarifados, que involucran a conocidos y, en muchas ocasiones, a sus propios familiares.

Percibir este problema social implica mirar fallas estructurales en la formación de generaciones que no solo llevan a que los valores se desdibujen, sino a que las situaciones de pobreza, miseria, violencia, falta de acceso a oportunidades, entre ellas, la justicia, la educación, la salud, el mínimo vital, sean una característica de las regiones donde se mueve más fácilmente en una economía subterránea el mercado del sexo con menores de edad.

\section{Antecedentes del flagelo}

Los viajes y el turismo asociados a la EsCNNA en Colombia, sumado a la pornografía infantil, son realidades que se han venido dando en aumento a lo largo del tiempo. Desde tiempos remotos, la sexualidad ha desempeñado un papel en el cual las dinámicas de la guerra, las conquistas, la política, la economía y la religión han estado presentes, y en este sentido, el modelo patriarcal hegemónico no ha sido tendiente a hacer prevalecer, ni proteger los derechos de los no favorecidos, entre ellos, por lo general, el de las mujeres y los menores de edad.

Sin embargo, pese a la "normalización" del uso de la fuerza sobre mujeres y menores de edad enmarcado por la costumbre, estos no tenían voz, y poco a poco con el paso de la historia las luchas y reivindicaciones sociales conllevaron que algunas sociedades, entre ellas las francesas e inglesas, repensaran los derechos en igualdad de condiciones para todos y se protegiera a los más débiles (Humbarita, 2015).

En cuanto al delito sexual en Colombia,

en el 2004, el Instituto Nacional de Medicina Legal y Ciencias Forenses, realizó 17.912 reconocimientos médico legales, directos e indirectos, observándose un incremento con respecto al año anterior de 3.673. Esto significa que porcentalmente se elevó en un 25,8 \%. En cuanto a las víctimas causa gran preocupación el hecho de que el 84,3\%, son menores de edad. Este grupo que comprende desde los 0 a los 17 años, registró 14.434 casos. Comparando esta cifra con la registrada en el año 2003, 11.886 casos, encontramos que se incrementó en un 21,4\%. (Instituto Nacional de Medicina Legal y Ciencias Forenses, s. f.) 
Estas cifras traen como consecuencia que las diferentes instituciones que tienen bajo su responsabilidad la protección de los menores de edad no concuerden frente a la estadística, de modo que es apenas para algunos un aproximado a la realidad a la cual están sometidos niños, niñas y adolescentes, toda vez que no se denuncia, ni ante la Policía, ni ante la Fiscalía, ni ante el Instituto Colombiano de Bienestar Familiar (ICBF), o en su caso no se llega a Medicina Legal. Por tanto, los subregristros, si bien son solo aproximaciones, no reflejan lo que verdaderamente acontece, y las actuaciones del derecho penal no llegan en la mayoría de los casos a la judicialización.

\section{El rol del Estado colombiano}

En nuestra sociedad, ha coexistido una vulneración hacia los derechos de niños, niñas y adolescentes, en que la explotación del ser humano ha supuesto que se asuma en muchos casos la "normalización" de la "prostitución" a temprana edad con menores de edad, cuando la prostitución corresponde a un mundo adulto, en que la autonomía y voluntariedad no son elementos a tomar cuando se involucran menores de edad para actividades sexuales o eróticas. Por tanto, romper con patrones socioculturales supone cambiar la manera como se ve y se asume el derecho, el cual parte desde lo preventivo y propositivo, y no necesariamente desde un rol reactivo de control y castigo mediante su acción punitiva, coercitiva y policiva.

Los esfuerzos del Estado colombiano aún no han logrado un significativo alcance para frenar la explotación sexual comercial de niños, niñas y adolescentes, pero aun así el trabajo mancomunado desempeñado por las autoridades y demás entes gubernativos no ha sido suficiente para evitar este flagelo, velar por la protección de los menores de edad, y en caso de haber sido vulnerados, resarcirlos y reivindicar sus derechos. Nuestro país en los últimos años ha tenido un fuerte señalamiento en cuanto a la protección de los derechos de niños, niñas y adolescentes, ya que el mal denominado turismo sexual sumado a la pornografía infantil ha sido un "paraíso" para nacionales y extranjeros, en que los fenotipos no necesariamente conducen a menores de edad por lo tradicional rubios, morenos, trigueños, sino niños y niñas indígenas tanto en las grandes urbes como en zonas de frontera.

La permisividad en algunos casos de las leyes colombianas es un factor crítico, así como el trabajo que realizan las autoridades no ha sido lo suficientemente coercitivo, ni propicio, pues el derecho internacional sobre la protección de los derechos 
humanos señala que el Estado debe hacer y fomentar políticas más drásticas para proteger esta población, puesto que el control muchas veces es ineficaz y no se le presta la atención y el cuidado que el tema amerita.

Entre las causas por las cuales hoy en día se siguen vulnerando los derechos de niños, niñas y adolescentes en Colombia, esta falta o calidad de la información por parte del Estado que permita tomar medidas preventivas en escuelas, colegios y centros universitarios, así como indicar y enseñar una cultura que se implante desde la familia para con los menores de edad. En tal sentido, la judicialización de quienes han perpetrado estos delitos es necesaria, para demostrar eficacia de la política pública y que se vuelva a creer en el aparato estatal, así como los mecanismos claros de denuncia y de restablecimiento de derechos.

Los viajes y el turismo van de la mano con las dificultades socioeconómicas, en los que los menores de edad se ven sometidos por propios o foráneos a ver su sexualidad como un negocio, enmarcado por cambios socioculturales, estados de necesidad económica, falta de empleo, acceso a oportunidades. Por tanto, el Estado debe desempeñar un papel activo en el control y la promoción, en los que haya un turismo responsable y se deje claro que niños, niñas y adolescentes no son objetos sexuales y que tener relaciones con menores de edad es un delito y tiene cárcel, tal como reza el eslogan de Migración Colombia.

\section{Normativa y jurisprudencia}

Con el fin de analizar si el Estado colombiano cumple los estándares normativos y jurisprudenciales referentes a los criterios acerca de las penas impuestas a los infractores de delitos sexuales cometidos contra menores de edad, se trae a colación diversos puntos de vista doctrinales y normativos, en tanto el Estado colombiano se fundamenta en el respeto, la protección, la garantía y la realización de los derechos fundamentales de las personas, entre los que se encuentran los derechos de los niños y su protección a todo tipo de vulneración o violación.

La Sentencia C-464/2014, de 9 de julio y la Sentencia T-718/2015, de 24 de noviembre "dan una visión de este Derecho de forma Constitucional que enmarca todo un análisis jurisprudencial al respecto”, permitiendo que los ciudadanos ejerzan sus derechos, y en caso de ser vulnerados, se les reivindiquen, así como establecer mecanismos de denuncia como herramienta principal en estos casos. Asimismo, la Sentencia C-853/2009, de 25 de noviembre expresa que 
la libertad sexual entre otros derechos tales como la libertad como contextos Constitucionales son de fundamental protección, del igual manera presenta la protección especial de los menores de 18 años mediante tres razones tales como la situación de fragilidad, la sociedad democrática y el déficit de representación política que presentan los menores.

Por su parte, la Sentencia C-318/2003, de 24 de abril denota que las medidas tomadas por el Gobierno no son suficientes ante la protección de los derechos de niños, niñas y adolescentes; por ende, hace referencia a que, "cuando se empiezan a vulnerar sus derechos y libertades, surge la responsabilidad del Estado Colombiano, siendo esta de naturaleza social”. Sin olvidar que la acción y la omisión son elementos por analizar cuando se cumplen funciones desde el Estado a través de sus instituciones y de sus operadores.

Mediante Sentencia C-085/2016, de 24 de febrero, se expresa:

La Corte Constitucional es consciente de que la Constitución no determina un modelo específico para la enseñanza de la educación sexual, y que no se puede por lo tanto exigir al Gobierno ni al legislador que implemente la educación sexual a través de cátedras específicas, cuando existen razones para hacerlo a través de proyectos pedagógicos transversales, pero también es consciente de que el interés superior de los niños, sus derechos prevalentes y su condición de sujetos de especial protección constitucional obligan al Estado colombiano a tomar todas las medidas necesarias para protegerlos en el máximo nivel posible y ello incluye tomar cartas en la solución inmediata y efectiva de las falencias que se puedan encontrar en los sistemas de educación para la sexualidad en todo el país, y particularmente en el sector rural y en las regiones en donde se ha evidenciado.

Por su parte, la Ley 1336/2009, de 21 de julio en lo referido a los delitos sexuales "adiciona y robustece la Ley 679 del año 2001, de lucha contra la explotación, la pornografía y el turismo sexual con niños, niñas y adolescentes”. El IcBF en el Boletín ESCNNA de 2018 referencia:

La explotación sexual comercial de la niñez es una violación fundamental de los derechos de la niñez. Abarca el abuso sexual por parte del adulto y remuneración en dinero o en especie para el niño o para una tercera persona o varias. El niño es 
tratado como objeto sexual y como mercancía. La explotación sexual comercial de la niñez constituye una forma de coerción y violencia contra esta, equivale al trabajo forzado y constituye una forma contemporánea de esclavitud.

Lo anterior permite traer a colación el libro De los delitos y de las penas (Beccaria, 2011) en el sentido de que se buscan identificar teorías sobre los delitos cometidos y cómo debería ser su apología, por lo que el hecho de ir más allá de la norma hacia la realidad social o desde esta al mundo normativo tendría que necesariamente implicar un contenido sociojurídico que permita enlazar en un Estado social de derecho los problemas que se viven a diario desde sus falencias o excesos normativos.

Cabrera (2011), en lo referido a los menores de edad, aduce que

las definiciones de delito sexual contenidas en el Código Penal pretenden salvaguardar la libertad sexual de las personas, en cuanto a la relación con los menores de edad, se entiende que, además de su derecho a vivir la sexualidad en condiciones de libertad, protegen su indemnidad sexual y su adecuado proceso de formación. Avala esta idea el hecho de que por debajo de los trece años se niegue a los menores capacidad para consentir válidamente una relación sexual y el hecho de que, una vez alcanzada la edad de trece años, les siga estando vetada la participación en ciertas actividades sexuales.

Por ende, Colombia es un país de leyes, por lo que en todo el sentido de la palabra el ordenamiento jurídico está completamente obligado a persuadir y penalizar los delitos y las infracciones cometidas contra los menores de edad. Si bien aún hace falta fortalecer la acción penal, es necesario repensar los roles que están asumiendo niños, niñas y adolescentes en una cultura en la que todo vale y en la que las dinámicas comerciales y económicas terminan permeando las formas de interactuar de los diferentes grupos sociales.

Bouyssou (2015) al respecto plantea que

la pornografía que utiliza como víctimas a niños y niñas destruye vidas porque el circuito que apela a la inhumanidad para cernirse sobre ellos en pro de la mercantilización, de la distribución de material pornográfico, así como el reclutamiento de víctimas de explotación sexual comercial, tiene garantizada su permanencia, y aún su incremento, en tanto y en cuanto los seres humanos insistan en valorizar 
lo humano, mediante la apropiación y destrucción de vidas infantiles y adolescentes. Este modelo horroroso impregna la cotidianeidad de los países denominados civilizados, y viola todos y cada uno de los derechos, de esos niños y jóvenes, sus derechos, y sus personas. (p. 13)

Por tanto, como refiere Olvera (2013),

las políticas públicas [...] se pueden implementar para proteger a las víctimas y sancionar a sus victimarios. Por ello, el análisis que se desarrolla no solo se concentra en la perspectiva penal, sino también en la política criminal que inicia desde cómo surge el problema y cuáles son los factores que lo favorecen, hasta las medidas de política social para su erradicación, sin faltar una análisis dogmático para determinar los bienes jurídicos tutelados, las conductas que deben tipificarse y diferenciarlas de otros delitos como el de trata de personas y el lenocinio. (p. 48)

Es entonces el turismo sexual un problema no solo nacional sino mundial que requiere políticas públicas contundentes en la protección de los derechos fundamentales de los menores. Por ende, las víctimas de delitos sexuales son menores de edad (niños, niñas y adolescentes) en los que el comercio sexual, la pornografía infantil y el turismo con fines sexuales no se denuncia por temor, amenazas, y en muchos casos, peligra su vida. Por ello, el trabajo y el deber de las autoridades por proteger sus derechos se hace una tarea muy compleja, pues no es suficiente la fuerza pública y personal capacitado para salvaguardar sus derechos. La ley colombiana castiga a los agresores y victimarios de niños, niñas y adolescentes; sin embargo, para lograr disminuir tales hechos, el Estado debería desarrollar una política pública más fuerte, eficaz y menos permisiva, para que los abusadores no continúen haciendo de las suyas violando los derechos de esta población en estado de vulnerabilidad (González, 2014).

\section{Bien jurídico por proteger}

El bien jurídico por proteger en los delitos referentes a la explotación sexual, comercial y la pornografía infantil, dentro del ordenamiento jurídico nacional, se refiere no solo a la libertad sexual de la que gozan niños, niñas y adolescentes, la cual conceptualiza Orts y Suárez-Mira (2001) como: 
La libertad sexual es antes que nada libertad, es decir, independencia de la voluntad, capacidad de determinación espontánea, en el ámbito de la sexualidad. Este es el contenido esencial de la libertad sexual, que se expande en varias direcciones: por un lado, engloba la facultad de escoger y practicar, en cada momento, la opción sexual que más plazca y, ligado a él, la de utilizar y servirse del propio cuerpo en la esfera sexual, sin más limitaciones que las derivadas del obligado respeto a la libertad ajena; de otra, la posibilidad de elegir al partenaire, con su consentimiento y de rechazar las proposiciones no deseadas. (p. 17)

Por otro lado, está la dignidad del menor en tanto está relacionada con la libertad de la que goza física, moral y espiritualmente, la cual es definida en la Sentencia T-881/2002, de 17 de octubre como

(i) la dignidad humana entendida como autonomía o como posibilidad de diseñar un plan vital y de determinarse según sus características (vivir como quiera), (ii) la dignidad humana entendida como ciertas condiciones materiales concretas de existencia (vivir bien) y (iii) la dignidad humana entendida como intangibilidad de los bienes no patrimoniales, integridad física e integridad moral (vivir sin humillaciones).

A esto se suma el desarrollo y la moral sexual como bienes jurídicos protegidos dentro de los delitos sexuales contra menores. El proceso de desarrollo tanto físico como psíquico que se cumple desde la infancia a la adolescencia contiene un factor fundamental dentro del desarrollo sexual del menor, que al someterse a estos delitos rompe el esquema normal de su desarrollo y crea en sí mismo como la pérdida de identidad o factores asociados a la vulneración de dignidad de niños, niñas y adolescentes (Duque, 2015).

\section{Datos en Colombia de la Escnna: pornografía infantil}

Si bien las cifras evidencian una realidad, las inferencias que se hacen desde los diferentes órganos que las investigan no necesariamente son unánimes. Por ejemplo, para el Fondo de las Naciones Unidas para la Infancia (Unicef, s. f.),

aproximadamente 35 mil niños y niñas menores de 18 años son explotados sexualmente en Colombia. / Se ha detectado en la última década un aumento del número 
de niños y niñas inducidos a la prostitución y una creciente inducción en edades más tempranas, inclusive antes de los 10 años. / En su gran mayoría los niños y niñas han sido víctimas de violencia en el hogar, de abandono, de abuso sexual o de expulsión del sector educativo. / Entre 1992 y 1997 ingresaron a los tribunales colombianos 42 casos de mujeres víctimas de trata de personas. El método más frecuente de engaño son las ofertas para trabajar en el exterior, aprovechando las necesidades de trabajo e ingresos mayores y la ingenuidad de las personas. Las ciudades colombianas de donde han salido más víctimas han sido Bogotá, Pereira, Cali y Medellín. Los destinos más frecuentes han sido Japón, España, Holanda, Alemania, Suiza, Italia, Hong Kong y Singapur. (pp. 40-41)

En el caso colombiano, un estudio conjunto realizado entre la Universidad de Cartagena, el icb y y la Fundación Renacer en 2004 refiere que, "en la ciudad de Cartagena de Indias, se detectó que de los 189 casos registrados de EsnnA, el 93,65 \% son niñas, frente a un 6,34 \% de niños víctimas" (Bernal-Camargo et al., 2013, p. 624) (figuras 1, 2 y 3 ).

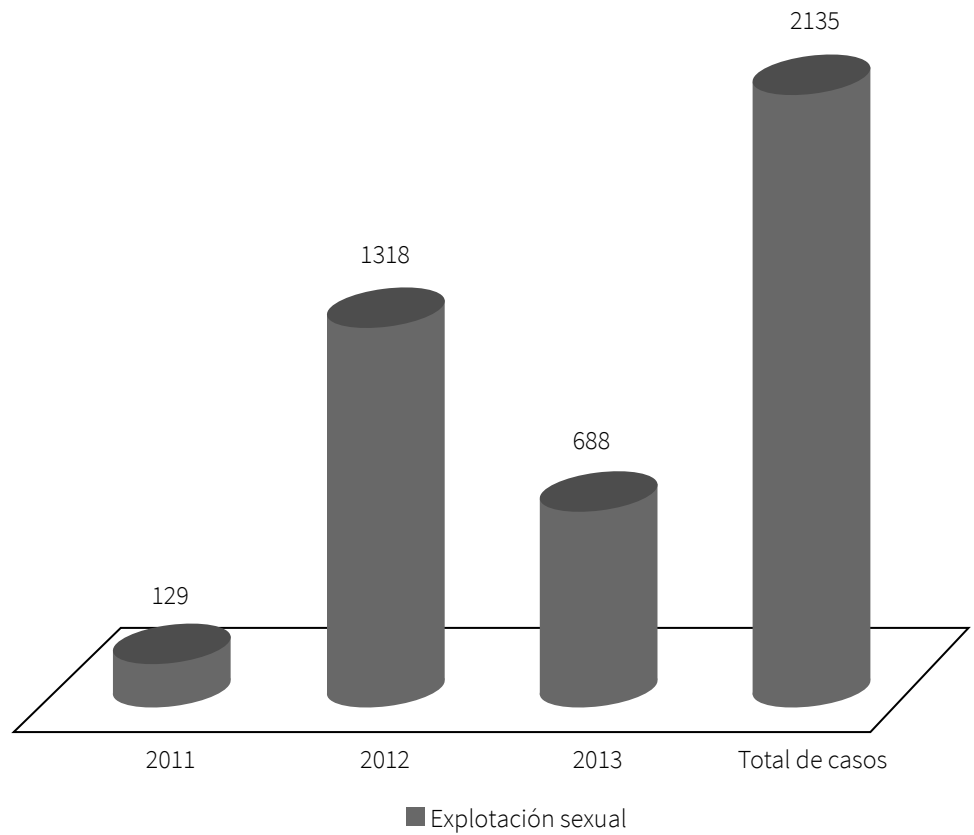

Fuente: ICbF. Cálculos del Observatorio del Bienestar de la Niñez. Datos consolidados desde 2011 hasta el 30 de septiembre de 2013 . 
Figura 1. Número de casos que ingresan al Proceso Administrativo de Restablecimiento de Derechos (PARD) por el delito de explotación sexual comercial consolidado desde 2011 hasta septiembre de 2013 según motivo de ingreso.

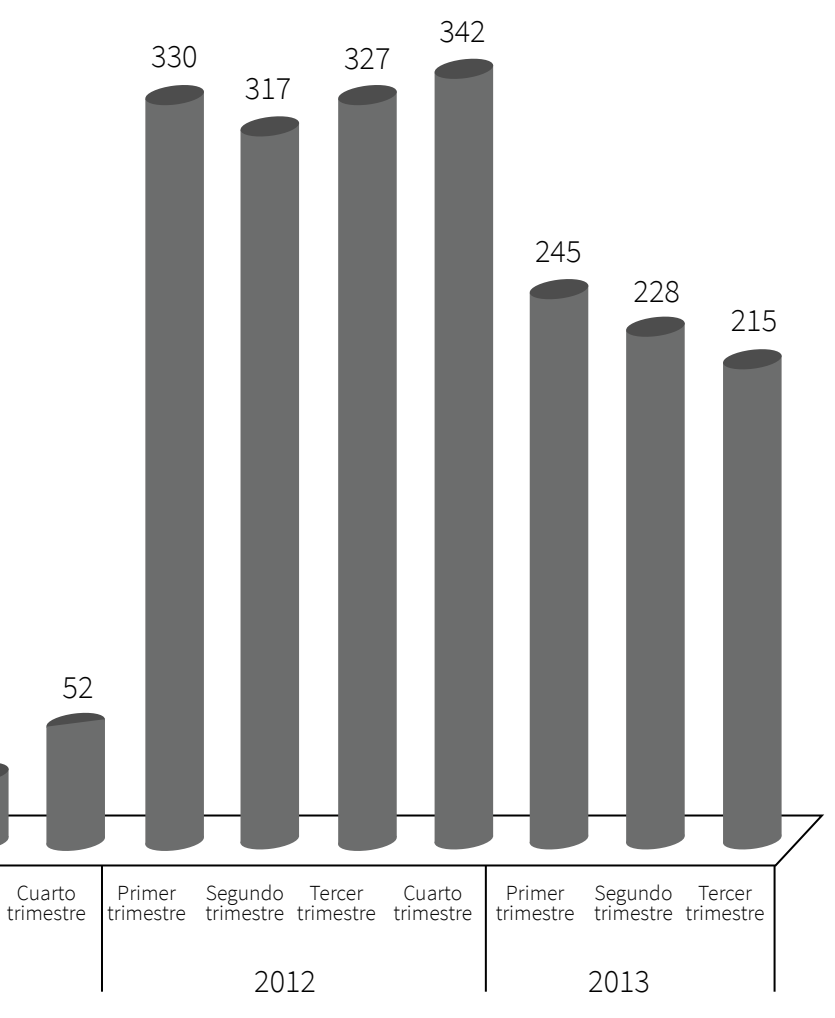

Explotación sexual

Fuente: ICBF. Cálculos del Observatorio del Bienestar de la Niñez. Datos consolidados desde 2011 hasta el 30 de septiembre de 2013 .

Figura 2. Número de casos que ingresan al PARD por el delito de explotación sexual comercial para los trimestres de 2011-2013 según motivo de ingreso. 


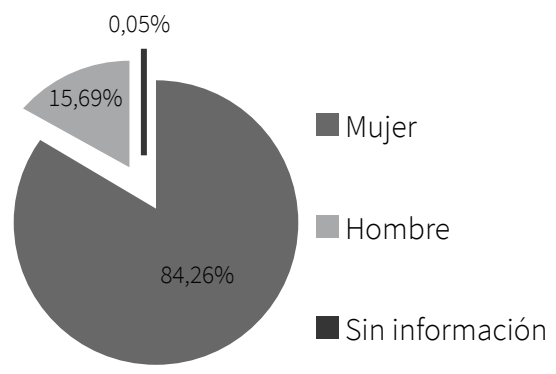

Fuente: ICBF. Cálculos del Observatorio del Bienestar de la Niñez. Datos consolidados desde 2011 hasta el 30 de septiembre de 2013 .

Figura 3. Porcentaje de ingresos al PARD por el delito de explotación sexual comercial desde 2011 hasta septiembre de 2013 según sexo.

En esta perspectiva,

es importante resaltar que para el 2011 y 2012 el mayor y menor número de ingresos al Proceso Administrativo de Restablecimiento de Derechos se presentó para los mismos trimestres. En este sentido, el mayor número de ingresos ocurrió en el cuarto trimestre para cada año y el menor registro se presentó en el segundo trimestre. En cambio, entre el 10 de enero al 30 de septiembre de 2013, el trimestre donde se registraron más ingresos por el delito de Explotación Sexual Comercial fue en el primer trimestre. Y el trimestre con menor número de ingresos para el 2013 se presentó en el tercer trimestre. (p. 42)

Para Colombia, la explotación sexual de menores es un escenario que anualmente recauda más de USD 35000 millones. Referente a estudios realizados por el ICBF, se entiende que el 87 \% de las víctimas de explotación sexual son menores de edad, dentro de los cuales el $82 \%$ se encuentran en edades entre 12 y 17 años.

E1 Procurador recordó que en Colombia el turismo creció en más del 150 por ciento entre los años 2010 y 2017. Años en los que el turismo en el país pasó de 2,6 millones a 6,5 millones de visitantes, de los cuales un alto porcentaje está llegando a Cartagena... De los 234 cruceros que han llegado al país, 218 fueron a Cartagena, la ciudad recibe el 13 por ciento del total de turistas internacionales, pero para nadie es un secreto que a muchos de los turistas de cruceros, hombres maduros, 
les ofrecen niños y niñas con fines de explotación sexual... Pese a que la Justicia colombiana cuenta con más de 10 leyes que penalizan estos delitos, el acceso a la justicia sigue siendo una tortura para las víctimas, que en la mayoría de los casos no denuncian. (El Tiempo, 2018)

Pese a los esfuerzos por detener la explotación sexual, el comercio y la pornografía infantil, los índices cada día son más desalentadores, pues son crímenes organizados, mas no transitorios, como se pensaría referente al turismo sexual.

Frente a la intervención, se busca prevenir y erradicar los delitos de explotación sexual, comercialización y pornografía infantil que atenta contra la integridad de los menores de edad, como de incentivar las denuncias, atender y restituir los derechos de niños, niñas y adolescentes mediante políticas como:

- Asesorar a las entidades institucionales y a sus funcionarios en cuanto a la detección y prevención como procesos de restitución de derechos en cuanto a los delitos sexuales, específicamente explotación, comercialización y pornografía de niños, niñas y adolescentes.

- Desarrollar proyectos que eviten el turismo sexual en las ciudades más turísticas que son prestas a este tipo de explotación.

- Incentivar y desarrollar la normativa ya vigente en el ordenamiento jurídico para que sea efectiva y más agresiva a este tipo de delitos.

Lo anterior en respuesta a los modelos de crimen organizado que se instauran en las diferentes ciudades que aprovechan los vacíos y las necesidades de unos grupos poblacionales específicos.

\section{Conclusiones}

Es de resaltar que es una ardua labor la que no solo le compete al Estado colombiano, sino que es deber de cada ciudadano interactuar, persuadir e indicar a esta población las facultades y leyes que los protegen de flagelos como el abuso sexual, la pornografía y el turismo sexual, en los que niños, niñas y adolescentes día a día son atraídos y engañados con el único fin de ser victimizados y tristemente casos en los que las víctimas son asesinadas, amedrentadas o simplemente nosotros como sociedad los excluimos. 
Sin embargo, hay entidades no gubernamentales que tienen su mirada en esta población, así como el derecho internacional, la Convención sobre los Derechos del Niño, entre otros tratados internacionales, por lo que Colombia ha hecho un esfuerzo por ceñirse y acogerse a estos, pero la tarea debe ser unánime para que la implementación de los reglamentos y estatutos que cada corporación tiene sean implementados de la forma más correcta e idónea para salvaguardar los derechos y deberes de esta comunidad.

\section{Referencias}

Aguilar Cárceles, M. M. (2009). Abuso sexual en la infancia. Anales del Derecho, 27, 210-240.

Beccaria, C. (2011). De los delitos y de las penas. Ciudad de México, México: Fondo de Cultura Económica.

Bernal-Camargo, D. R., Varón-Mejía, A., Becerra-Barbosa, A., Chaib-De Mares, K., Seco-Martín, E. y Archila-Delgado, L. (2013). Explotación sexual de niños, niñas y adolescentes: modelo de intervención. Revista Latinoamericana de Ciencias Sociales, Niñez y Juventud, 11(2), 617-632. DOI:https://doi.org/10.11600/1692715x.11211260512

Bouyssou, N. I. (2015). Los delitos de corrupción de menores y pornografía infantil (Tesis doctoral, Universidad de Sevilla, Sevilla, España).

Cabrera Maerín, M. (2011). Los menores frente a los delitos sexuales. Critica. Recuperado de http://www.revista-critica.com/la-revista/monografico/ analisis/560-los-menores-frente-a-los-delitos-sexuales

Casas Arguello, M. L. y Fernández de Alba, N. (2016, mayo 18). Explotación sexual infantil en Colombia. Cine-Derechos Humanos UR [Video]. Recuperado de https://www. youtube.com/watch?v=Uih4124r6iQ

Díaz Pérez, A. (2000). Los delitos contra la libertad, integridad y formación sexuales (Tesis de grado, Universidad de La Sabana, Chía, Colombia). Recuperado de https://intellectum. unisabana.edu.co/bitstream/handle/10818/5274/129854.pdf?sequence=1 
Duque Ayala, C. (2015). El control constitucional de la justicia transicional en Colombia frente a los requerimientos de la Corte Interamericana de Derechos Humanos. Verba Iuris, 33, 77-97.

El Tiempo (2018, abril 9). Colombia pierde en la lucha contra la explotación sexual infantil. Recuperado de https://www.eltiempo.com/colombia/otras-ciudades/ colombia-pierde-en-la-lucha-contra-la-explotacion-sexual-infantil-203130

Fondo de las Naciones Unidas para la Infancia. (s. f.). La niñez colombiana en cifras. Recuperado de https://www.unicef.org/colombia/pdf/cifras.pdf

Fondo de las Naciones Unidas para la Infancia. (2015). Abuso sexual infantil: cuestiones relevantes para su tratamiento en la justicia. Montevideo, Uruguay: Autor.

González Noriega, O. (2014). La Corte Constitucional como agente del campo jurídico colombiano: la omisión legislativa de principios constitucionales. IUSTA, 2(41), 123137. DOI: https://doi.org/10.15332/s1900-0448.2014.0041.01

Humbarita, J. I. (2015). Derecho constitucional hispanoamericano frente a la realidad institucional: manifiesta divergencia. IUSTA, 2(43), 91-118. DOI: https://doi.org/10.15332/ s1900-0448.2015.0043.03

Ibarra Sánchez, E. (2014). Protección de niños en la red: sexting, ciberbullyng y pornográfia infantil. Recuperado de https://archivos.juridicas.unam.mx/www/bjv/libros/8/3646/5.pdf

Instituto Colombiano de Bienestar Familiar (2014). Análisis de la situación de explotación sexual comercial en Colombia: una oportunidad para garantizar la protección de niños, niñas y adolescentes. Bogotá, Colombia: Autor. Recuperado de https://www.icbf.gov.co/sites/ default/files/publicacion-51.pdf

Instituto Nacional de Medicina Legal y Ciencias Forenses (s. f.). Delito sexual. Recuperado de http://www.medicinalegal.gov.co/documents/20143/49490/Delito+Sexual.pdf

Ley 599/2000, de 24 de julio, por la cual se expide el Código Penal.

Ley 1098/2006, de 8 de noviembre, por la cual se expide el Código de la Infancia y la Adolescencia. 
Ley 1236/2008, de 23 de julio, por medio de la cual se modifican algunos artículos del Código Penal relativos a delitos de abuso sexual.

Ley 1336/2009, de 21 de julio, por medio de la cual se adiciona y robustece la Ley 679 de 2001, de lucha contra la explotación, la pornografía y el turismo sexual con niños, niñas $\mathrm{y}$ adolescentes.

La Rosa Cortina, J. M. de (2011). Los delitos de pornografia infantil: aspectospenales, procesales y criminológicos. Valencia, España: Tirant Lo Blanch.

Morlachetti, A. (2014). La Convención sobre los Derechos del Niño y la protección de la infancia en la normativa internacional de derechos humanos. En J. F. Beltrão et al., Derechos humanos de los grupos vulnerables (pp. 21-42). Red de Derechos Humanos y Educación Superior. Recuperado de http://www.consorciodh.ufpa.br/livros/DHGV Manual.pdf\#page=21

Olvera Lezama, B. I. (2013). Turismo sexual infantil: políticas públicas para su prevención. Ciudad de México, México: Ubijus.

Orts Berenguer, E. y Suárez-Mira Rodríguez, C. (2001). Los delitos contra la libertad e indemnidad sexuales. Valencia, España: Tirant Lo Blanch.

Sentencia T-881/2002, de 17 de octubre, principio de dignidad humana.

Sentencia C-318/2003, de 24 de abril, tratado internacional.

Sentencia C-853/2009, de 25 de noviembre, libertad de configuración legislativa en política criminal.

Sentencia C-464/2014, de 9 de julio, reforma al Código Penal.

Sentencia T-718/2015, de 24 de noviembre, delitos sexuales contra menores de edad.

Sentencia C-085/2016, de 24 de febrero, normas para prevención de violencia sexual y atención integral de niños, niñas y adolescentes abusados sexualmente. 